\title{
Conformal radiotherapy for lung cancer: interobservers' variability in the definition of gross tumor volume between radiologists and radiotherapists
}

\author{
Chiang J Tyng*1, Rubens Chojniak ${ }^{1}$, Paula NV Pinto ${ }^{1}$, Marcelle A Borba ${ }^{1}$, \\ Almir GV Bitencourt ${ }^{1}$, Ricardo C Fogaroli ${ }^{2}$, Douglas G Castro $^{2}$ and \\ Paulo E Novaes ${ }^{2}$
}

\begin{abstract}
Address: ${ }^{1}$ Department of Diagnostic Imaging, Hospital A C Camargo, Rua Prof. Antônio Prudente, 211, São Paulo SP, Brazil and ${ }^{2}$ Department of Radiotheraphy, Hospital A C Camargo, Rua Prof. Antônio Prudente, 211, São Paulo SP, Brazil

Email: Chiang J Tyng* - chiangjengtyng@uol.com.br; Rubens Chojniak - chojniak@uol.com.br; Paula NV Pinto - nicolebarbosa@terra.com.br; Marcelle A Borba - marcelle.alvesborba@gmail.com; Almir GV Bitencourt - almirgvb@yahoo.com.br;

Ricardo C Fogaroli - rcfogaroli@terra.com.br; Douglas G Castro - dougguedes@uol.com.br; Paulo E Novaes - novaespe@uol.com.br

* Corresponding author
\end{abstract}

Published: 5 August 2009

Radiation Oncology 2009, 4:28 doi:10.1186/1748-717X-4-28

This article is available from: http://www.ro-journal.com/content/4/I/28

(C) 2009 Tyng et al; licensee BioMed Central Ltd.

This is an Open Access article distributed under the terms of the Creative Commons Attribution License (http://creativecommons.org/licenses/by/2.0), which permits unrestricted use, distribution, and reproduction in any medium, provided the original work is properly cited.
Received: 4 April 2009

Accepted: 5 August 2009

\begin{abstract}
Background: Conformal external radiotherapy aims to improve tumor control by boosting tumor dose, reducing morbidity and sparing healthy tissues. To meet this objective careful visualization of the tumor and adjacent areas is required. However, one of the major issues to be solved in this context is the volumetric definition of the targets. This study proposes to compare the gross volume of lung tumors as delineated by specialized radiologists and radiotherapists of a cancer center.

Methods: Chest CT scans of a total of 23 patients all with non-small cell lung cancer, not submitted to surgery, eligible and referred to conformal radiotherapy on the Hospital A. C. Camargo (São Paulo, Brazil), during the year 2004 were analyzed. All cases were delineated by 2 radiologists and 2 radiotherapists. Only the gross tumor volume and the enlarged lymph nodes were delineated. As such, four gross tumor volumes were achieved for each one of the 23 patients.

Results: There was a significant positive correlation between the 2 measurements (among the radiotherapists, radiologists and intra-class) and there was randomness in the distribution of data within the constructed confidence interval.
\end{abstract}

Conclusion: There were no significant differences in the definition of gross tumor volume between radiologists and radiotherapists.

\section{Background}

Lung cancer is becoming increasingly frequent in both genders worldwide. Three-dimensional conformal radiotherapy has been utilized for non-small-cell lung cancer, especially for those in advanced stage or for the inoperable early-stage diseases. Conformal external radiotherapy is based on the extensive use of modern medical imaging techniques, efficient dosimetric software, accurate patient 
positioning methods, stringent verification and quality control of procedures, aiming to increase tumor control by boosting tumor dose, reducing morbidity and sparing healthy tissues. Refined visualization of the tumor and adjacent areas is required to attain this objective.

Computerized planning has to calculate with accuracy and show the dose throughout the irradiated volume of the patient, taking into account the shape of the field and the modification devices of the beams used to obtain a conformal and homogeneous dose in the target volume. The idea of giving shape to the radiation fields, in order to shape only the target volume, is referred to as "targetdriven planning" and is the primary difference between conformal (3D) and conventional (2D) radiotherapy. Conformal radiotherapy permits better adaptation of the dosimetric distribution to the tumor volume, reduction of healthy organs exposure, and on the long term, higher dose of tumor irradiation [1-5].

The volume of the tumor mass (gross tumor volume) represents the area of greatest concentration of tumor cells. It is usually defined as the tumor clinically evident and visible in imaging studies, such as computed tomography or magnetic resonance. The appropriate use of the imaging study is crucial upon definition of tumor volume.

In the majority of cases, toxicities of degrees 3 to 5 are lower than $10 \%$ in patients tested with higher doses, using three-dimensional conformal radiation therapy techniques [6-8].

However, one of the most difficult problems to solve in this context is the volumetric definition of targets $[5,9,10]$. The high precision of this radiotherapic technique demands a stringent and qualified approach by means of therapeutic preparation procedures $[11,12]$. Methodological rules should be established for volumetric definition of targets, taking into account the difficulties in delineating the macroscopic volume of the target and its microscopic involvement [5,13-15].

Delineation is generally performed in many centers by radiotherapists who often have no training or experience in radiology, making it harder to accurately identify the details of anatomic structures in computed tomography imaging. With the more generalized use of conformal radiotherapy and other new technologies, the immediate need of assuring the quality control in the definition of gross tumor volume was evidenced [16].

On the other hand, although radiologists are better qualified to interpret radiological anatomy, they are not always familiar with the natural history of the disease. Differences in delineation can, therefore, be observed among physicians due to imprecise tomographic data or divergent planning. These differences have already been reported in literature for delineation of prostate, lungs, central nervous system or esophagus tumors [9,17-23], but the magnitude of all these differences is still not completely assessed.

The objective of this study is to compare the delineation of gross tumor volume of lung tumors among experienced radiologists and radiotherapists from an oncology reference center on Brazil.

\section{Methods}

Chest CT scans of all the patients with non-small-cell lung cancer, not submitted to surgery and referred to conformal radiotherapy of Hospital A. C. Camargo (São Paulo, Brazil) during the year 2004 were analyzed.

All the tomographic exams were performed in the adequate position for treatment in the same tomography equipment (GE HiSPEED), with identical acquisition parameters and injection of endovenous contrast medium. Each acquisition was carried out in patients with apnea, in the helicoidal mode, with pitch of 1 and slice thickness of $7 \mathrm{~mm}$ reconstructed every $5 \mathrm{~mm}$.

A total group of 23 patients was analyzed, of which 9 were females and 14 males. The average age was 69 years, ranging from 53 to 85 years. At the time of the diagnosis, 5 were in clinical stage IB; 5 , in IIB; 6 , in IIIA; 6 , in IIIB; and 1 , in IV.

The 23 cases were delineated by two radiologists and two radiotherapists from Hospital A. C. Camargo.

Each physician has received a written summary of the medical records of each patient. Only the gross tumor volume (i.e., the visible primary tumor and the enlarged lymph nodes) was delineated. According to definitions of the International Commission on Radiation Units and Measurements-ICRU $(1993,1999)$ the gross tumor volume is the visible or palpable tumor extension. As regards lymph nodes, those whose smaller axis diameter is larger than or equal to $1 \mathrm{~cm}$ are considered compromised. The lymph nodes were included in the delineation of the gross tumor volume, when located close to the primary tumor, or were delineated separately, if distant. We analyzed the gross tumor volume as a whole: both the primary tumor and the enlarged lymph nodes in each section. The optimal visualization parameters were defined in a prior study, with $-600 / 1600 \mathrm{UH}$ for the pulmonary window and $+20 / 400$ for the mediastinal window considered mandatory for delineation [24]. The magnification factor was chosen by the physician. The previous delineation was recorded, but was not made available to the other 
physicians. For gross tumor volume calculation, delineation was performed with the ECLIPSE $^{\circledast}$ software from VARIAN with the electronic cursor in each tomographic section, being thus the tumor area multiplied by the slice thickness, and the total volume resulted from the sum of the tumor volume of all slices. In this manner, we obtained 4 gross tumor volumes for each one of the 23 patients.

The measurements were initially analyzed descriptively by means of the averages calculation, as well as the standard deviations and medians and the observation of minimum and maximum values.

The statistical methods utilized were Pearson's correlation coefficient, the Bland-Altman plot, the intraclass correlation coefficient described by Fleiss and the coefficient of variation. The level of significance utilized for the tests was $5 \%$.

\section{Results}

Table 1 shows the average, standard deviation, median, minimum and maximum values observed by the radiologists and radiotherapists.

Analyzing the measurements of the radiotherapists, we can see represented in figure 1 , the two measurements of the radiotherapists and the value of Pearson's correlation coefficient, in which we observe significant and positive correlation between the two measurements. The intraclass correlation coefficient for the radiotherapist is 0.989 (p < $0.001)$ with confidence interval of $95 \%$ equal to $(0.974$; $0.995)$.

We can also evaluate this concordance by the Bland-Altman method. The graph representing this analysis is showed in Figure 2. The differences between the measurements ranged from 42.88 to 37.74 , with average of 3.10 and standard deviation of 21.15. Thus we obtained a confidence interval of $95 \%$ equal to $(-39.20 ; 45.41)$.

Analyzing the radiologists' findings, Figure 3 shows the measurements they attained and the value of Pearson's correlation coefficient, in which we observe significant and positive correlation between the two measurements. The intraclass correlation coefficient is equal to 0.762 (p < $0.001)$ with confidence interval of $95 \%$ equal to $(0.522$; $0.891)$.

We can also evaluate this congruity by the Bland-Altman method. Figure 4 shows the graph representing this analysis. The differences between the measurements ranged from -466.27 to 26.23 with average of -31.35 and standard deviation of 101.27, thus we obtained a confidence interval of $95 \%$ equal to $(-233.88 ; 171.18)$.

Analyzing radiotherapists and radiologists findings, we utilized the average between the measurements of the radiologists and the average of the measurements of the radiotherapists.

Figure 5 represents the measurements of the radiologists and of the radiotherapists and the value of Pearson's correlation coefficient, in which we observe significant and positive correlation between the two measurements. The intraclass correlation coefficient is equal to 0.942 (p < 0.001 ) with confidence interval of $95 \%$ equal to $(0.869$; $0.975)$. Hence an excellent correlation between the two measurements has been found.

We can also evaluate this congruity by the Bland-Altman method. The graph representing this analysis is contained in figure 6 . The differences between the measurements ranged from -192.09 to 50.14 with average of -3.51 and standard deviation of 48.73, thus we obtained a confidence interval of $95 \%$ equal to $(-100.98 ; 93.95)$.

In table 2, we calculate the coefficient of variation among the 4 measurements, to wit: those of the 2 radiotherapists and those of the 2 radiologists, which once again indicates good congruity among them, with the exception of only one value.

\section{Discussion}

Inoperable lung cancer prognosis remains very poor. Besides the alternate fractionated schemes and combined

Table I: Values of average, standard deviation, median, minimum and maximum of the values observed by the radiologists and radiotherapists

\begin{tabular}{llllll}
\hline Observer & Average & SD & Median & Minimum & Maximum \\
\hline Radiotherapist I & 140.84 & 136.29 & 83.56 & 13.03 & 516.85 \\
Radiotherapist 2 & 137.74 & 141.68 & 78.81 & 11.22 & 496.39 \\
Average & 139.29 & 138.61 & 74.44 & 12.13 & 496.26 \\
Radiologist 1 & 127.13 & 128.03 & 72.36 & 13.87 & 450.26 \\
Radiologist 2 & 158.48 & 169.21 & 65.36 & 12.09 & 547.91 \\
Average & 142.80 & 141.24 & 68.27 & 12.98 & 465.35
\end{tabular}




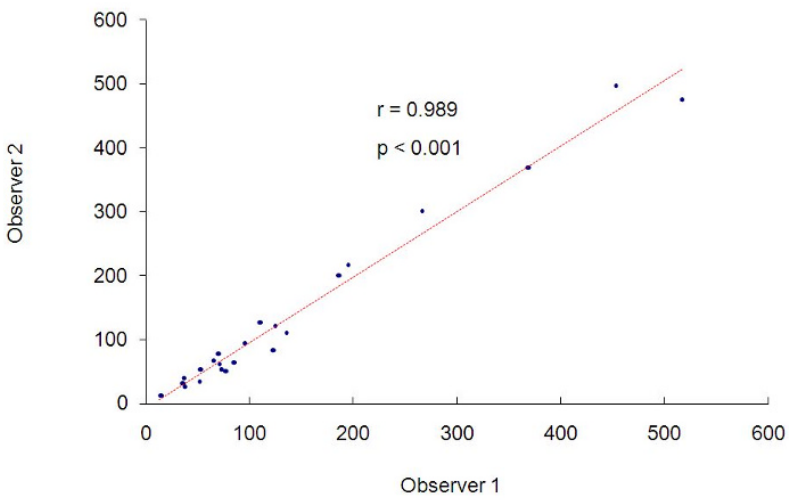

Figure I

Measurements of the radiotherapists and the value of Pearson's correlation coefficient.

therapies, new planning strategies, including conformal radiotherapy and dose increase, are under investigation [25-29].

It is known that the general survival rate, cause-specific survival and local tumor control are directly correlated with the gross tumor volume in $\mathrm{cm} 3$. In the multivariate analysis the most predictive independent survival variable is the gross tumor volume [30].

Recently, the data mentioned by LEUNENS et al. (1993), evidenced that the gross tumor volume definition is not that simple, and there can be risks in excessive confidence in the medical capacity to estimate the tumor extension with the imaging approaches [17].

Due to the number of uncertainties and of phenomena related to the tumor, the definition of gross tumor volume

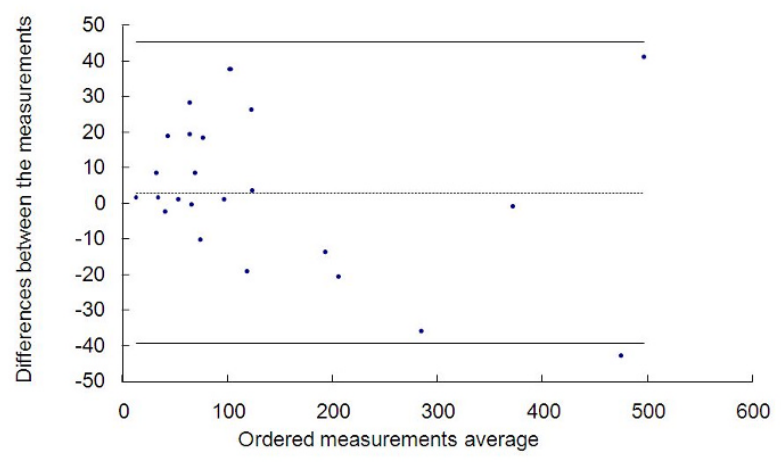

Figure 2

Measurements of the radiotherapists and the graph by the Bland-Altman method.

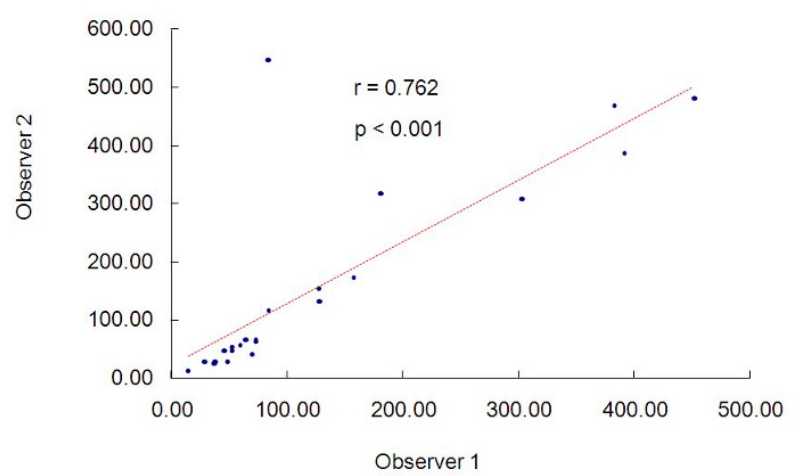

Figure 3

Measurements of the radiologists and the value of Pearson's correlation coefficients.

in thoracic radiotherapy could result in greater volume variations $[22,27,31,32]$, focused on the definition of lung cancer gross tumor volume as part of a delineation protocol. The three authors concluded that there is significant variation in target volume definition.

VAN DE STEENE et al. (2002), showed unexpected major interobservers' variability, with tumor delineation varying by several centimeters, due to:

1) difficulty in discriminating between tumor and atelectasia;

2) difficulty in distinguishing normal and pathological structures of the tumor;

3) use of different tomographic windows and partial volume effects;

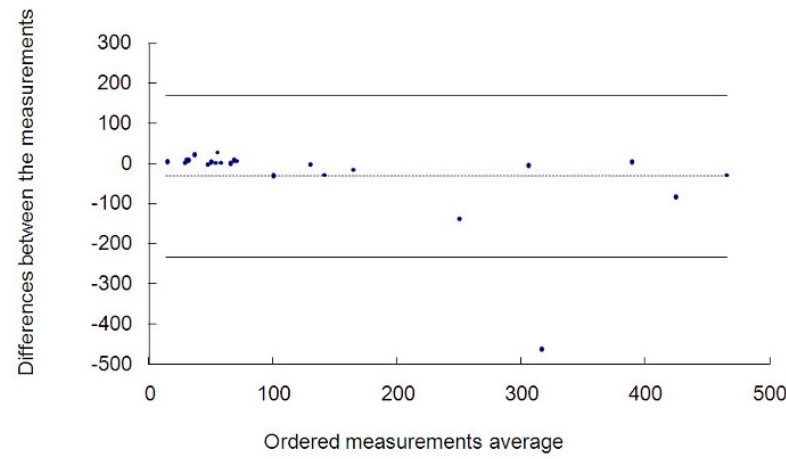

Figure 4

Measurements of the radiologists and the graph by the Bland-Altman method. 


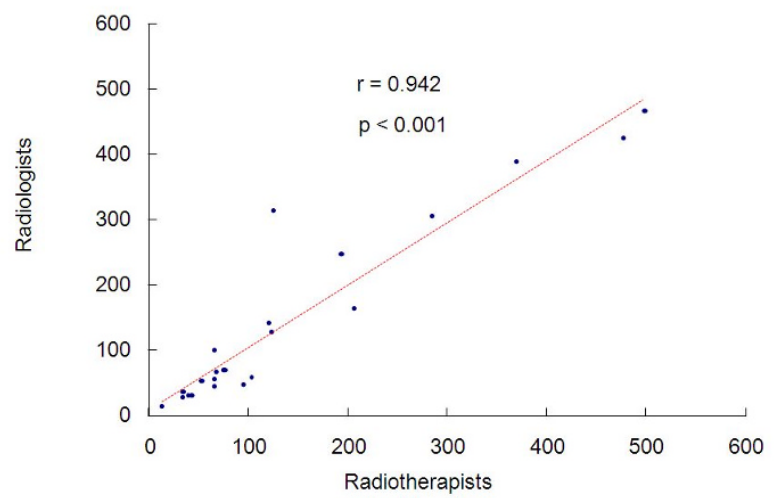

Figure 5

Measurements of the radiotherapists and the radiologists and the value of Pearson's correlation coefficient.

4) insufficient anatomic knowledge [33].

Another study carried out by GIRAUD et al. (2002) that compared the delineation of gross tumor volume performed by radiologists and radiotherapists, showed significant differences between the two groups: radiologists tended to delineate lower and more homogeneous volumes than radiotherapists, especially in the "difficult" cases [34]. The delineation of the target volume and highrisk organ constitutes a critical stage in conformal radiotherapy $[5,9,10,13,35]$ and the subsequent steps are dependent on correct gross-volume delineation. Field shaping and dose planning are based exclusively on the tumor volumes and critical normal tissue delineated. GIRAUD et al. (2002) suggested that the correct definition of the gross tumor volume can be attained, when radiotherapists are well trained in chest imaging [34]. SUNDAR

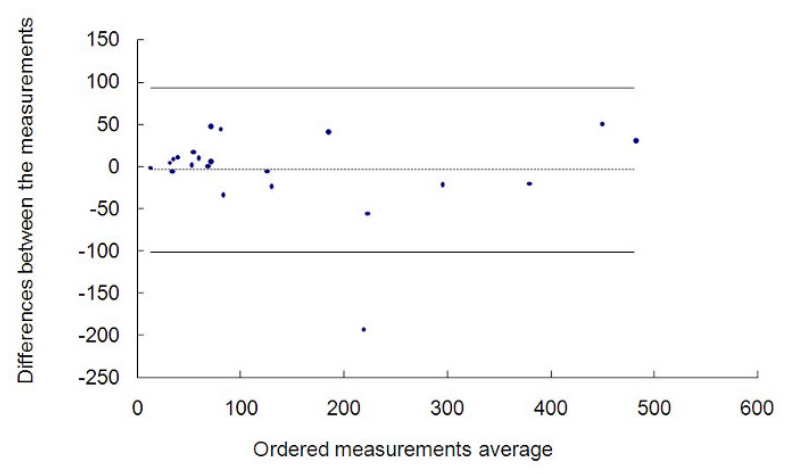

\section{Figure 6}

Measurements of the radiotherapists and the radiologists and the graph by the Bland-Altman method. and SYMONDS (2002) suggest a compulsory period of structured training in section imaging diagnosis for radiotherapists [36].

According to the recommendations of ICRU 50 (1991, 1993 ) and later on, of ICRU 62 (1999), gross tumor volume delineation should be performed as close as possible to the tumor and/or lymph node, without adding any safety margin [37-39]. Successive additional volumes are designated taking into account other treatment uncertainties. A second attitude adopted by the majority consists of attempting to distinguish between the tumor tissue and the surrounding collapsed parenchyma. This choice calls for perfect tomographic acquisition with rapid injection of the contrast medium and a first series of slices performed immediately after the injection [18].

Our results were incompatible with those of VAN DE STEENE et al. (1996), SENAN et al. (1999) and GIRAUD et al. (2002), which exhibited significant differences in lung tumor delineation $[22,34,40]$.

In our study there was excellent intraclass correlation (Pearson's correlation coefficient) in the case of the radiotherapists and good correlation in the case of the radiologists. In the latter, the correlation was slightly lower due to a single point at which there was greater discrepancy between the first and the second measurement. In the analysis of radiotherapists and radiologists, we also observed excellent correlation between the two measurements.

Congruity was also evaluated by the Bland-Altman method, while randomness was observed in the distribution of data within the constructed confidence interval, and only one point fell outside the interval, indicating that the error among the measurements does not tend to increase when the measurement values are higher. Moreover, the average of the differences was close to zero, indicating good concordance between the two measurements.

The discrepant measurement of gross tumor volume of one of the radiologists resulted from associated atelectasis that constitutes the main cause of error in tumor volume delineation. We emphasize that in our study, we observed one case of tumor with mediastinal invasion, two with invasion of the thoracic wall and two causing lung atelectasis.

Some peculiarities of Hospital A. C. Camargo might have contributed to these results, such as integration of the radiotherapy and diagnostic imaging departments, internship of the radiotherapy residents in diagnostic imaging with learning of sectional anatomy, and geographical proximity of the radiology and radiotherapy departments, 
Table 2: Coefficient of variation (COV) among the 4 measurements ( 2 radiologists and 2 radiotherapists)

\begin{tabular}{|c|c|c|c|c|c|c|}
\hline Patient & Radiotherapist I & Radiotherapist 2 & Radiologist I & Radiologist 2 & Average & cov \\
\hline I & 108.55 & 127.42 & 127.29 & 155.28 & 129.64 & 0.15 \\
\hline 2 & 369.29 & 370.13 & 391.36 & 387.46 & 379.56 & 0.03 \\
\hline 3 & 125.05 & 121.29 & 125.97 & 130.56 & 125.72 & 0.03 \\
\hline 4 & 13.03 & 11.22 & 13.87 & 12.09 & 12.55 & 0.09 \\
\hline 5 & 52.13 & 33.13 & 35.87 & 27.78 & 37.23 & 0.28 \\
\hline 6 & 68.45 & 78.81 & 72.54 & 65.36 & 71.29 & 0.08 \\
\hline 7 & 83.56 & 65.31 & 72.36 & 64.18 & 71.35 & 0.12 \\
\hline 8 & 35.90 & 27.40 & 46.20 & 27.02 & 34.13 & 0.26 \\
\hline 9 & 77.58 & 49.27 & 67.62 & 41.39 & 58.97 & 0.28 \\
\hline 10 & $135.9 \mid$ & 109.46 & 81.64 & 547.91 & 218.73 & 1.01 \\
\hline II & 65.30 & 65.82 & 83.64 & 116.94 & 82.93 & 0.29 \\
\hline 12 & 186.47 & 199.94 & 178.92 & 317.77 & 220.78 & 0.30 \\
\hline 13 & 453.51 & 496.39 & 382.78 & 466.78 & 449.87 & 0.11 \\
\hline 14 & 33.94 & 32.31 & 28.72 & 28.98 & 30.99 & 0.08 \\
\hline 15 & $|95.4|$ & 215.96 & 157.15 & 172.20 & 185.18 & 0.14 \\
\hline 16 & 71.31 & 62.83 & 64.20 & 67.13 & 66.37 & 0.06 \\
\hline 17 & 53.26 & 52.13 & 52.19 & 51.76 & 52.34 & 0.01 \\
\hline 18 & 516.85 & 475.67 & 450.26 & 480.44 & 480.81 & 0.06 \\
\hline 19 & 266.67 & 302.54 & 303.24 & 308.28 & 295.18 & 0.06 \\
\hline 20 & 95.41 & 94.10 & 50.23 & 46.40 & 71.54 & 0.38 \\
\hline 21 & 121.23 & 83.49 & 59.19 & 56.56 & 80.12 & 0.37 \\
\hline 22 & 73.29 & 53.71 & 43.71 & 47.11 & 54.46 & 0.24 \\
\hline 23 & 37.24 & 39.65 & 34.97 & 25.58 & 34.36 & 0.18 \\
\hline
\end{tabular}

which are located in the same building, on adjacent floors.

Despite of there are no statistically significant differences in the definition of gross tumor volume between radiologists and radiotherapists in this study, in nine of twentythree evaluated patients there was a difference greater than $20 \%$, which can be clinically relevant. Most of these cases involved primary tumors located close to the mediastinum or chest wall, which hindered the proper measurement of the lesions. Regardless of the overlapping volumes have not been assessed, in neither case the observers considered different structures to delineate the target volumes.

Recently some authors have shown that delineation accuracy can be improved by using fluorodeoxyglucose-positron emission tomography (FDG-PET)/CT information. FDG-PET/CT is a functional study that has proved to be more accurate than CT in determining extent of nonsmall-cell lung cancer. Integration of FDG-PET/CT on the volume delineation can reduce interobserver variation compared with CT based delineation and alter gross tumor volume in about $50 \%$ of the cases. [41,42] FDGPET/CT images are particularly useful in defining the target volume in the presence of atelectasis and in defining involved lymph nodes. [43]

\section{Conclusion}

Radiotheraphy plays an important role in the management of inoperable lung cancer patients, A precise and consistent delineation of target volumes is needed to improve treatment and avoid complications. Although some authors have found large rates of interobserver variability on volume delineation for lung cancer, in this survey, there was no statistically significant difference in the definition of gross tumor volume between radiotherapists and radiologists or intraclasses. Some institutional characteristics should be responsible for this finding, such as integration between radiotherapy and diagnostic imaging departments.

\section{Competing interests}

The authors declare that they have no competing interests.

\section{Authors' contributions}

CJT conceived of the study, and participated in its design, acquisition, analysis and interpretation of data, and helped to draft the manuscript.

RC and PEN conceived of the study, and participated in its design and coordination, and helped to draft the manuscript.

PNVP, RCF and DGC conceived of the study, and participated in its design, acquisition of data, and helped to draft the manuscript.

$M A B$ and AGVB have been involved in literature review, drafting the manuscript and revising it critically for publication. 
All authors have given final approval of the version to be published.

\section{References}

I. Emami B, Lyman J, Brown A, Coia L, Goitein M, Munzenrider JE, Shank $B$, Solin LJ, Wesson M: Tolerance of normal tissue to therapeutic irradiation. Int J Radiat Oncol Biol Phys 1991, 2 I: 109-22.

2. Emami B, Purdy JA, Manolis J, Barest G, Cheng E, Coia L, Doppke K, Galvin J, LoSasso T, Matthews J, Munzenrider J, Shank B: Threedimensional treatment planning for lung cancer. Int J Radiat Oncol Biol Phys 1991, 21:217-27.

3. Emami B: Three-dimensional conformal radiation therapy in bronchogenic carcinoma. Semin Radiat Oncol 1996, 6:92-7.

4. Armstrong J, Zelefsky M, Leibel S, Burman C, Han C, Harrison LB, Kutcher GJ, Fuks ZY: Strategy for dose escalation using 3dimensional conformal radiation therapy for lung cancer. Ann Oncol 1995, 6:693-7.

5. Armstrong J: Target volume definition for three-dimensional conformal radiation therapy of lung cancer. Br J Radiol 1998, 7I:587-94.

6. Graham MV, Purdy JA, Emami B, Matthews JW, Harms WB: Preliminary results of a prospective trial using three dimensional radiotherapy for lung cancer. Int J Radiat Oncol Biol Phys 1995, 33:993-1000.

7. Sibley GS, Mundt AJ, Shapiro C, Jacobs R, Chen G, Weichselbaum R, Vijayakumar $S$ : The treatment of stage III nonsmall cell lung cancer using high dose conformal radiotherapy. Int J Radiat Oncol Biol Phys 1995, 33:1001-7.

8. Armstrong J, Raben A, Zelefsky M, Burt M, Leibel S, Burman C, Kutcher G, Harrison L, Hahn C, Ginsberg R, Rusch V, Kris M, Fuks Z: Promising survival with three-dimensional conformal radiation therapy for non-small cell lung cancer. Radiother Oncol 1997, 44:17-22.

9. Beckendorf V, Elles S, Madelis G: Postoperative radiation therapy in lung cancer: clinical target volume delineation in a workshop including radiation oncologist and radiologists [abstract]. Radiother Oncol 2000, 56(Supl I):S39. [Presented at 19th Annual ESTRO Meeting, 2000 Sept 1923; Istanbul]

10. Antolak JA, Rosen II: Planning target volumes for radiotherapy: how much margin is needed? Int J Radiat Oncol Biol Phys 1999, 44: II 65-70.

II. Perez CA: The critical need for accurate treatment planning and quality control in radiation therapy. Int J Radiat Oncol Biol Phys 1977, 2:815-8.

12. Perez CA, Stanley K, Grundy G, Hanson W, Rubin P, Kramer S, Brady LW, Marks JE, Perez-Tamayo R, Brown GS, Concannon JP, Rotman $M$ : Impact of irradiation technique and tumour control and survival of patients with unresectable non-oat cell carcinoma of the lung. Cancer 1982, 50:1091-9.

13. Ekberg L, Holmberg O, Wittgren L, Bjelkengren G, Landberg T: What margins should be added to the clinical target volume in radiotherapy treatment planning for lung cancer? Radiother Oncol 1998, 48:71-7.

14. Giraud Ph, Antoine M, Larrouy A, Milleron B, Callard P, De Rycke Y, Carette MF, Rosenwald JC, Cosset JM, Housset M, Touboul E: Evaluation of microscopic tumor extension in non-small-cell lung cancer for three-dimensional conformal radiotherapy planning. Int J Radiat Oncol Biol Phys 2000, 48: 10I5-24.

15. Jaffray DA, Yan D, Wong JW: Managing geometric uncertainty in conformal intensity-modulated radiation therapy. Semin Radiat Oncol 1999, 9:4-19.

16. McNee SG, Rampling R, Dale AJ, Gregor A: An audit of 3D treatment planning facilities and practice in the UK. Clin Oncol 1998, 10:18-23.

17. Leunens G, Menten J, Weltens C, Verstraete J, Schueren E van der: Quality assessment of medical decision making in radiation oncology: variability in target volume delineation for brain tumours. Radiother Oncol 1993, 29:169-75.

18. Satoh K, Kobayashi T, Kawase Y, Mitani M, Takahashi K, Takashima $\mathrm{H}$, Ohkawa M, Tanabe M, Kojima K: CT-pathologic correlation in the tumour margins of lung cancer. Radiat Med 1996, 14:167-72.

19. Cazzaniga LF, Marinoni MA, Bossi A, Bianchi E, Cagna E, Cosentino D, Scandolaro L, Valli M, Frigerio M: Interphysician variability in defining the planning target volume in the irradiation of prostate and seminal vesicles. Radiother Oncol 1998, 47:293-6.

20. Oozeer R, Chauvet B, Toy BJ, Berger C, Garcia R, Felix-Faure C, Le Thanh $H$, Reboul $F$ : Definition of prostatic contours using tomodensitometric slices: study of differences among radiation oncologists and between examinations. Cancer Radiother 1999, 3:333-40.

21. Rasch C, Barillot I, Remeijer P, Touw A, van Herk M, Lebesque JV: Definition of the prostate in CT and MRI: a multi-observer study. Int J Radiat Oncol Biol Phys 1999, 43:57-66.

22. Senan S, van Sornsen de Koste JS, Samson M, Tankink H, Jansen P, Nowak PJ, Krol AD, Schmitz P, Lagerwaard FJ: Evaluation of a target contouring protocol for 3D conformal radiotherapy in non-small cell lung cancer. Radiother Oncol 1999, 53:247-55.

23. Tai P, Van Dyk J, Yu E, Battista J, Stitt L, Coad T: Variability of target volume delineation in cervical esophageal cancer. Int J Radiat Oncol Biol Phys 1998, 42:277-88.

24. Giraud Ph, Dubray B, Gaboriaud G, Rosenwald JC, Cosset JM: Influence of CT images visualization parameters for target volume delineation in lung cancer [abstract]. Radiother Oncol 2000, 56(SupI I):S39. [Presented at 19th Annual ESTRO Meeting, 2000 Sept 1923; Istanbul]

25. Armstrong J, Burman C, Leibel S, Fontenla D, Kutcher G, Zelefsky M, Fuks Z: Three-dimensional conformal radiation therapy may improve the therapeutic ratio of high dose radiation therapy for lung cancer. Int J Radiat Oncol Biol Phys 1993, 26:685-9.

26. Graham MV, Matthews JW, Harms WB Sr, Emami B, Glazer HS, Purdy JA: Three-dimensional radiation treatment planning study for patients with carcinoma of the lung. Int J Radiat Oncol Biol Phys 1994, 29: I 105- 17.

27. Graham MV, Purdy JA, Emami B, Matthews JW, Harms WB: Preliminary results of a prospective trial using three dimensional radiotherapy for lung cancer. Int J Radiat Oncol Biol Phys 1995, 33:993-1000.

28. Vijayakumar S, Chen GT: Implementation of three dimensional conformal radiation therapy: prospects opportunities, and challenges. Int J Radiat Oncol Biol Phys 1995, 33:979-83.

29. Robertson JM, Ten Haken RK, Hazuka MB, Turrisi AT, Martel MK, Pu AT, Littles JF, Martinez FJ, Francis IR, Quint LE, Lichter AS: Dose escalation for non-small cell lung cancer using conformal radiation therapy. Int J Radiat Oncol Biol Phys 1997, 37:1079-85.

30. Bradley JD, Leumwananonthachai N, Purgy JA, Wasserman TH, Lockett MA, Graham MV, Perez CA: Gross tumor volume, critical prognostic factor in patients treated with three-dimensional conformal radiation therapy for non-small-cell lung carcinoma. Int J Radiat Oncol Bio 2002, 52:49-57.

31. Hamilton CS, Denham JW, Joseph DJ, Lamb DS, Spry NA, Gray AJ, Atkinson CH, Wynne CJ, Abdelaal A, Bydder PV, Chapman PJ, Matthews JHL, Stevens G, Ball D, Kearsley J, Ashcroft JB, Janke P, Gutmann A: Treatment and planning decisions in non-small cell carcinoma of the lung: an Australasian patterns of practice study. Clin Oncol R Coll Radiol 1992, 4:I4I-7.

32. Valley JF, Mirimanoff RO: Comparison of treatment techniques for lung cancer. Radiother Oncol 1993, 28:168-73.

33. Steene J Van de, Linthout N, de Mey J, Vinh-Hung V, Classens C, Noppen M, Bel A, Storme G: Definition of gross tumour volume in lung cancer: inter-observer variability. Radiother Oncol 2002, 62:37-49.

34. Giraud P, Elles S, Helfre S, De Rycke Y, Servois V, Carette MF, Alzieu C, Bondiau PY, Dubray B, Touboul E, Housset M, Rosenwald JC, Cosset JM: Conformal radiotherapy for lung cancer: different delineation of the gross tumor volume (GTV) by radiologists and radiation oncologists. Radiother Oncol 2002, 62:27-36.

35. Logue JP, Sharrock CL, Cowan RA, Read G, Marrs J, Mott D: Clinical variability of target volume description in conformal radiotherapy planning. Int J Radiat Oncol Biol Phys 1998, 41:929-31.

36. Sundar S, Symonds RP: Diagnostic radiology for radiotherapist: the case for structured training in cross-sectional imaging (CT and MRI). Clin Oncol 2002, I 4:413-4.

37. [ICRU] International Commission on Radiation Units and Measurements: Prescribing, recording and reporting photon beam therapy. Washington, DC: ICRU; I99I. (ICRU Report 50)

38. [ICRU] International Commission on Radiation Units and Measurements: Prescribing, recording, and reporting photon beam therapy. Bethesda MD: ICRU; 1993. (ICRU Report 50) 
39. [ICRU] International Commission on Radiation Units and Measurements: Prescribing, recording, and reporting photon beam therapy (supplement to ICRU Report 50). Bethesda. MD: ICRU; 1999. (ICRU Report 62)

40. Steene J Van de, Linthout N, de Mey J, Vinh-Hung V, Claassens C, Noppen M, Bel A, Storme G: Definition of gross tumor volume in lung cancer: inter-observer variability. Radiother Oncol 2002, 62:37-49.

4I. Faria SL, Menard S, Devic S, Sirois C, Souhami L, Lisbona R, Freeman CR: Impact of FDG-PET/CT on radiotherapy volume delineation in non-small-cell lung cancer and correlation of imaging stage with pathologic findings. Int J Radiat Oncol Biol Phys 2008, 70: 1035-1038.

42. Van Baardwijk A, Bosmans G, Boersma L, Buijsen J, Wanders S, Hochstenbag M, van Suylen RJ, Dekker A, Dehing-Oberije C, Houben R, Bentzen SM, van Kroonenburgh M, Lambin P, De Ruysscher D: PETCT-based auto-contouring in non-small-cell lung cancer correlates with pathology and reduces interobserver variability in the delineation of the primary tumor and involved nodal volumes. Int J Radiat Oncol Biol Phys 2007, 68:77I-778.

43. Greco C, Rosenzweig K, Cascini GL, Tamburrini O: Current status of PET/CT for tumour volume definition in radiotherapy treatment planning for non-small cell lung cancer (NSCLC). Lung Cancer 2007, 57:125-134.

Publish with Bio Med Central and every scientist can read your work free of charge

"BioMed Central will be the most significant development for disseminating the results of biomedical research in our lifetime. "

Sir Paul Nurse, Cancer Research UK

Your research papers will be:

- available free of charge to the entire biomedical community

- peer reviewed and published immediately upon acceptance

- cited in PubMed and archived on PubMed Central

- yours - you keep the copyright

Submit your manuscript here:

http://www.biomedcentral.com/info/publishing_adv.asp
BiolMedcentral 